\title{
Fibrin cross-linking in congenital factor XIII deficiency
}

\author{
F RODEGHIERO AND T BARBUI
}

From the Divisione di Ematologia, Ospedale Generale Regionale, Vicenza, Italy

SUMMARY Homozygous patients with factor XIII deficiency are devoid of immunologically identifiable A protein, the active enzymatic component. Quantitative studies of transamidase activity of the factor are available in only a few cases, and the fibrin cross-linking pattern is not well known. The present paper deals with the quantitative estimation of factor XIII transamidase activity (dansylcadaverine system), factor XIII molecular subunits, and the corresponding fibrin cross-linking pattern in seven homozygous patients with factor XIII deficiency. The results indicate that transamidase activity was present in all patients, and the range was $0.5-1 \cdot 7 \%$. The pattern of fibrin stabilisation showed an absence of cross-linking in two patients, the presence of $\gamma$ - $\gamma$-dimers (traces) in four, and $\gamma-\gamma$-dimers plus incomplete $\alpha$-polymers (traces) in one patient. In conclusion, the homozygous patients reported here were not completely devoid of functioning factor XIII.

Plasma factor XIII, the fibrin stabilising factor, is a zymogen which, after activation by thrombin, ${ }^{1}$ catalyses the formation of $\epsilon(\gamma$-glutamyl $)$ lysine cross-links between fibrin monomers. ${ }^{2}$ The zymogen contains two types of subunits and, according to Bohn et al.,$^{3}$ the subunit plasma structure is $\mathrm{A}_{2} \mathrm{~S}$. Subunit $\mathbf{A}$ is the enzymatically active component whereas subunit $S$ plays a role in regulating the rate of calcium-dependent activation of the zymogen. ${ }^{4}$

Patients with severe factor XIII congenital deficiency are devoid of immunologically identifiable A protein but retain, albeit in reduced amount, subunit $\mathbf{S}^{\text {. }}{ }^{-8}$

The minimum level of factor XIII activity requested for normal haemostasis has been evaluated at between 1 and $2 \% .^{910}$ Moreover, the clinical expression of this haemorrhagic disorder is variable, and one could admit a relationship between the residual enzymatic activity and the severity of crosslinking impairment. Since this relation has been studied in only isolated cases, ${ }^{11-13}$ we report here the values of the specific enzymatic activity, the molecular subunit components, and the fibrin cross-linking pattern in seven homozygotes for factor XIII deficiency.

\section{Material and methods}

The patients have been reported previously. ${ }^{8}$ They

Received for publication 5 November 1979 had not received blood components during the last three months. Case 1 had not been transfused for one year before the present study. Blood was collected into 0.1 vol $3.8 \%$ sodium citrate anticoagulant and centrifuged at $1500 \mathrm{~g}$ for 20 minutes and deep frozen $\left(-30^{\circ} \mathrm{C}\right)$. The transamidase activity was measured, as previously reported ${ }^{14}$ using the fluorimetric method described by Lorand et al..$^{15}$ employing Dansylcadaverine (Sigma) and Hammarsten-casein, respectively, as donor and recipient for the amide group in the transamidase reaction. In order to render the method more sensitive, amine incorporation was stopped 60 minutes later, instead of 30 minutes as described by Lorand. The enzymatic activity of each plasma was calculated as the difference between the fluorescence emitted by the test plasma and that of the blank (control mixture including the plasma of the same subject with only the monodansylcadaverine missing but otherwise similarly treated). The calibration curve was constructed by diluting a pool of 10 normal plasmas at $1: 20,1: 40,1: 80,1: 160,1: 320$ in saline, and a linear relationship between the rate of amine incorporation and plasma concentration was obtained. In order to exclude the presence of some transamidating activity in the thrombin, the test was repeated omitting plasma; dansylcadaverine failed completely to be incorporated into casein. All plasmas from homozygous patients were examined for transamidase activity with or without the enzyme activation induced by thrombin. 
Subunits $\mathbf{A}$ and $\mathbf{S}$ were determined immunologically in agarose gel containing antibodies according to the Laurell technique ${ }^{1617}$ as previously reported. 78

Dodecylsulphate-polyacrilamide gel electrophoresis of solubilised reduced fibrin was performed according to Weber and Osborn ${ }^{18}$ principles, as previously reported. ${ }^{19}$ Fibrin was prepared from plasma according to Finlayson and Morton. ${ }^{20}$ $0.1 \mathrm{ml}$ of plasma was placed in a glass test tube $(5 \times 75 \mathrm{~mm})$ and mixed with $0.1 \mathrm{ml}$ of Michelis buffer $0.05 \mathrm{M} \mathrm{pH} 7 \cdot 3$ containing $30 \mathrm{mmol} / 1$ cysteine. To this mixture, brought to $37^{\circ} \mathrm{C}$ in a water bath, $0.01 \mathrm{ml}$ of thrombin (test-thrombin Behringwerke) diluted at $60 \mathrm{NIH} \mathrm{U} / \mathrm{ml}$ in $0.25 \mathrm{M} \mathrm{CaCl}_{2}$ (or $0.03 \mathrm{M}$ EDTA) was added. Clots formed in all test tubes and were wound, as they formed, on glass rods of $2.5 \mathrm{~mm}$ diameter. After 2 hours at $37^{\circ} \mathrm{C}$, the clots, still attached to the rods, were removed from the formed clot liquor for washing. Each clot was washed by immersing the rod to which it was attached in $200 \mathrm{ml}$ of refrigerated saline stirred at $4^{\circ} \mathrm{C}$. After 3 minutes the clot was carefully dried with filter paper; this procedure was repeated three times. After the final washing step each clot was placed in a test tube $(5 \times 75 \mathrm{~mm})$ containing $0.3 \mathrm{ml}$ of urea $9 \mathrm{M}$, sodium-dodecylsulphate (SDS) $3 \%$ and beta-mercaptoethanol $3 \%$ in sodium phosphate $0.04 \mathrm{M} \mathrm{pH} \mathrm{7 \cdot 1.} \mathrm{After} \mathrm{incubation,} \mathrm{with} \mathrm{occasional}$ stirring in a water bath at $37^{\circ} \mathrm{C}$ for 16 hours (during which time all clots were completely dissolved), $0.1 \mathrm{ml}$ aliquot was removed and mixed with $0.01 \mathrm{ml}$ blue bromophenol $(0.22 \%)$ and $0.02 \mathrm{ml}$ glycerin; $20 \mu \mathrm{l}$ of this mixture were submitted to electrophoresis.

Electrophoresis was performed using $125 \times 6 \mathrm{~mm}$ glass tubes filled up to $81 \mathrm{~mm}$ with polyacrylamide

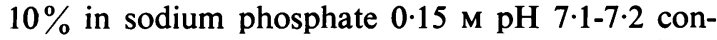
taining $0.1 \%$ SDS. Electrode buffer was sodium

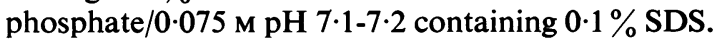
Electrophoresis at room temperature was carried out using 300B Bio Rad apparatus, for 1 hour at
$4 \mathrm{~mA} /$ tube and an additional 5 hours at $7 \mathrm{~mA} /$ tube (bromophenol blue at the bottom of the tube). The gels were stained in Coomassie brilliant blue (Serva). Normal fibrin obtained in the presence of $\mathrm{Ca}^{++}$showed $\alpha$-polymer and $\gamma$ - $\gamma$-dimer bands, whereas normal fibrin obtained in the presence of EDTA (not cross-linked) showed $\alpha, \beta$, and $\gamma$ monomer bands. No plasma protein contaminants were present except for a minimal trace of albumin migrating with the $\alpha$ chains. Furthermore, the thrombin used for testing fibrin cross-linking was found to be devoid of contaminating factor XIIIa, as shown by the appearance of the same pattern of cross-linking when recalcified plasma, instead of thrombin-clotted plasma, was used.

\section{Results}

The Table gives the factor XIII transamidase activity measured with and without thrombin activation and the molecular subunits of the factor and describes the fibrin stabilisation pattern observed in each patient's plasma.

Transamidase activity dependent on thrombin activation ranging from 0.50 to $1 \cdot 70 \%$ was detected in all homozygous patients. No fibrin cross-link was observed in two cases (3 and 5) whereas $\gamma$ - $\gamma$-dimers and $\gamma$ - $\gamma$-dimers plus incomplete $\alpha$ polymers were detected in four $(1,2,6,7)$ and one (4) cases respectively. It should be noted that case 4 had the highest transamidase plasma activity level. No enzymatic activity was measurable if thrombin was omitted. Subunit A was immunologically undetectable whereas subunit $\mathbf{S}$ was found to be low in all patients.

The Figure shows the fibrin stabilising pattern detected in the seven homozygous patients with factor XIII deficiency.

\section{Discussion}

The seven homozygous patients with congenital

Factor XIII molecular subunit plasma content, transamidase, and fibrin stabilising activity

\begin{tabular}{|c|c|c|c|c|c|}
\hline \multirow[t]{2}{*}{ Case } & \multicolumn{2}{|c|}{$H$ subunits $(\%)$} & \multicolumn{2}{|c|}{ Transamidase activity (\%) } & \multirow{2}{*}{$\begin{array}{l}\text { Fibrin stabilisation } \\
\text { pattern }\end{array}$} \\
\hline & $' A '$ & $' S$ ' & With thrombin & Without thrombin & \\
\hline $\begin{array}{l}1 \\
2 \\
3 \\
4 \\
5 \\
6 \\
7\end{array}$ & $\begin{array}{l}\text { Absent } \\
\text { Absent } \\
\text { Absent } \\
\text { Absent } \\
\text { Absent } \\
\text { Absent } \\
\text { Absent }\end{array}$ & $\begin{array}{l}30 \\
30 \\
50 \\
34 \\
33 \\
30 \\
20\end{array}$ & $\begin{array}{l}0.65 \\
0.60 \\
0 \cdot 50 \\
1 \cdot 70 \\
0 \cdot 80 \\
1 \cdot 00 \\
0 \cdot 80\end{array}$ & $\begin{array}{l}\text { Absent } \\
\text { Absent } \\
\text { Absent } \\
\text { Absent } \\
\text { Absent } \\
\text { Absent } \\
\text { Absent }\end{array}$ & $\begin{array}{l}\gamma \text { - } \gamma \text {-dimer (traces) } \\
\gamma \text { - } \gamma \text {-dimer (traces) } \\
\text { No stabilisation } \\
\gamma \text { - } \gamma \text {-dimer and } \alpha \text {-polymer (traces) } \\
\text { No stabilisation } \\
\gamma \text { - } \gamma \text {-dimer } \\
\gamma-\gamma \text {-dimer (traces) }\end{array}$ \\
\hline
\end{tabular}




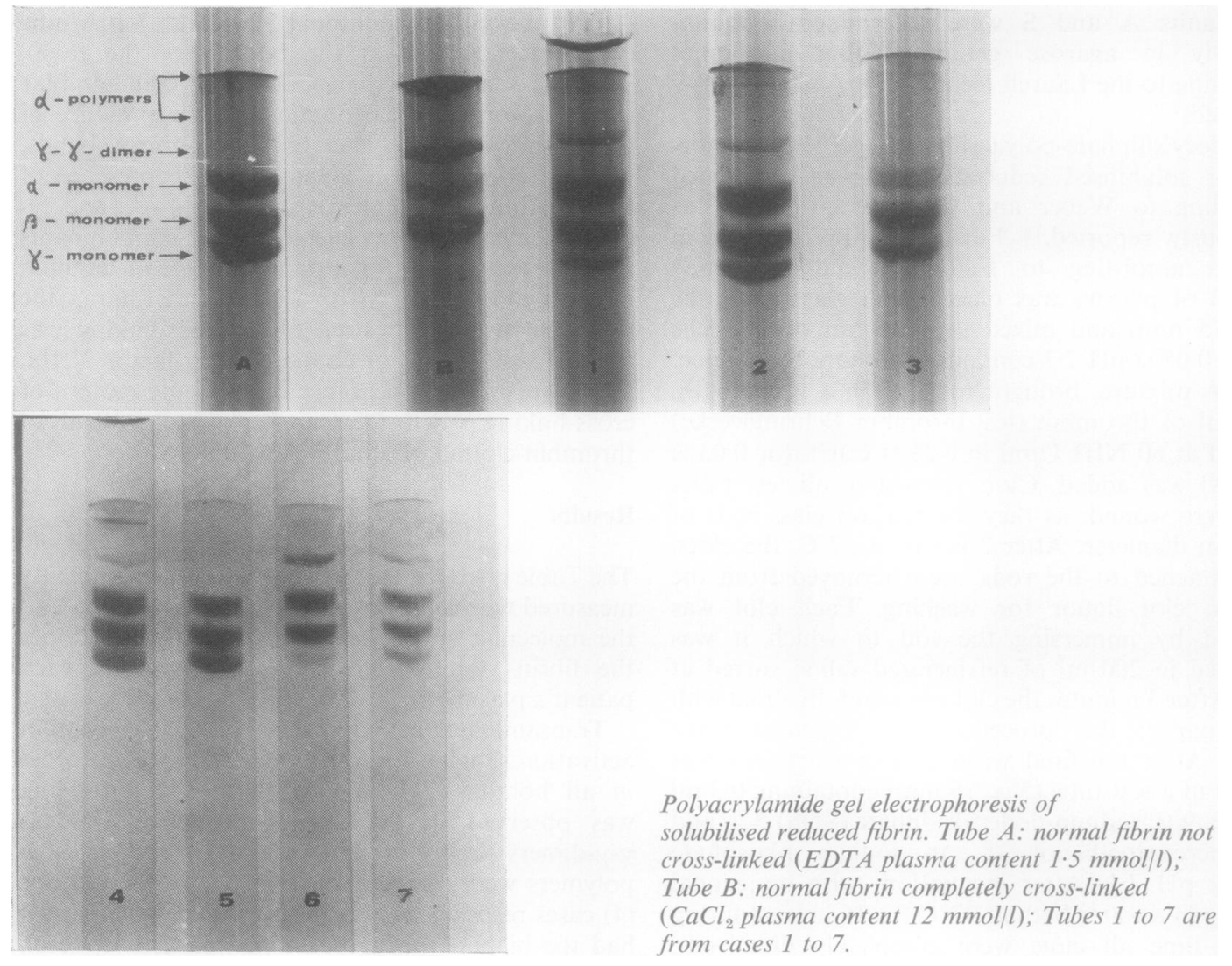

factor XIII deficiency here presented had plasma transamidating activity ranging from 0.5 to $1.7 \%$. In none of them was subunit $A$ measurable since the Laurell technique is not sensitive enough to measure levels below $5 \%$. Subunit $S$ has also been found to be reduced, and this finding could be due to a genetic mechanism which involves the two components. $^{8}$

The enzymatic activity found in these patients could be ascribed to a transamidating enzyme different from factor XIII. But the transamidase factor XIII is unique in requiring thrombin for its activation, and, when activated, there is an initial formation of $\gamma-\gamma$-dimer followed by $\alpha$-polymer formation. The pattern of polymerisation of fibrin monomer is quite different with other transamidases. ${ }^{21}$

In our study, the enzyme required thrombin for its transamidating activity and induced $\gamma$ - $\gamma$-dimers or $\gamma-\gamma$-dimers plus $\alpha$-polymers, showing that the sequence of the specific factor XIII action was respected. Thus this activity must be ascribed to factor XIII and not to other transamidating enzymes.

The activity found in our patients could be due to previous blood transfusion or could be an expression of a residual genetic synthesis. Considering that the half-life of plasma factor XIII is estimated at four to seven days 1022 we think it is unlikely that the activity we measured can represent that of transfusions which were stopped at least three months before the present study was begun.

In conclusion, these patients with congenital factor XIII deficiency are not completely devoid of functioning enzyme, which in different degrees induces a partial fibrin cross-linking. No clinical correlation could be drawn from these few cases. We hope that further studies, including sensitive and reliable methods for detecting factor XIII levels ranging from 0 to $2 \%$, will be able to demonstrate that, in this genetic disorder, the variable picture of haemorrhagic manifestations may be due to different degrees of genetic factor deficiency.

\section{References}

${ }^{1}$ Lorand L, Konishi K. Activation of the fibrin stabiliz- 
ing factor of plasma by thrombin. Arch Biochem Biophys 1964;105:58-67.

${ }^{2}$ Pisano JJ, Finlayson JS, Peyton MP. Crosslink in fibrin polymerized by factor XIII: $\epsilon-(\gamma$-glutamyl $)$ lysine. Science 1968;160:892-3.

${ }^{3}$ Bohn H, Haupt M, Kranz T. Die molekuläre Struktur der fibrinstabilisierenden Faktoren des Menschen. Blut 1972;25:235-48.

${ }^{4}$ Lorand L, Gray AJ, Brown K, Credo RB, Curtis CG. Dissociation of the subunit structure of fibrin stabilizating factor during activation of the zymogen. Biochem Biophys Res Comm 1974;56:914-22.

${ }^{5}$ Bohn $H$, Becker $W$, Trobisch $M$. Die molekuläre Struktur der fibrinstabilisierenden Faktoren des Menschen. II. Vergleichende immunologische Untersuchungen von Faktor-XIII-Mangelplasmen und Normalplasma. Blut 1973;26:303-11.

${ }^{6}$ Israels ED, Paraskevas F, Israels LG. Immunological studies of coagulation factor XIII. J Clin Invest 1973;52:2398-403.

7 Barbui T, Cartei G, Chisesi T, Dini E. Electroimmunoassay of plasma subunits $-\mathrm{A}$ and $-\mathrm{S}$ in a case of congenital fibrin stabilizing factor deficiency. Thromb Diath Haemorrh 1974;32:124-31.

${ }^{8}$ Barbui T, Rodeghiero F, Dini E, et al. Subunit A and S inheritance in four families with congenital factor XIII deficiency. Brit J Haemat 1978;38:267-71.

${ }^{9}$ Duckert F. Documentation of the plasma factor XIII deficiency in man. Ann N Y Acad Sci 1972;202:190-9.

${ }^{10}$ Ikkala E. Transfusion therapy in congenital deficiencies of plasma factor XIII. Ann N Y Acad Sci 1972;202: 200-3.

11 Pisano JJ, Finlayson JS, Peyton MP, Nagai Y. $\epsilon$-( $\gamma$-glutamyl)lysine in fibrin: lack of crosslink formation in Factor XIII deficiency. Proc Nat Acad Sci $1971 ; 68: 770-2$.

${ }^{12}$ Duckert F. Importance physiologique du facteur stabilisant la fibrine (facteur XIII). Schweiz Med Wochenschr 1974;104:1342-7.

${ }^{13}$ McDonagh J, McDonagh RP, Myllylä G, Ikkala E. Factor XIII deficiency: a genetic study of two affected kindreds in Finland. Blood 1974;43:327-32.

${ }^{14}$ Rodeghiero F, Barbui T, Battista R, Chisesi T, Rigoni G, Dini E. Molecular subunits and transamidase activity of factor XIII during disseminated intravascular coagulation in acute leukemia. Thromb Haemost 1980 ; in press.

${ }^{15}$ Lorand L, Urayama T, De Kiewiet JWC, Nossel HL. Diagnostic and genetic studies on fibrin-stabilizing factor with a new assay based on amine incorporation. J Clin Invest 1969;48:1054-64.

${ }^{16}$ Laurell CB. Quantitative estimation of proteins by electrophoresis in agarose gel containing antibodies. Anal Biochem 1966;15:45-52.

${ }^{17}$ Laurell CR. Electroimmunoassay. Scand J Clin Lab Invest 1972;29:suppl 124, 21-37.

${ }^{18}$ Weber $\mathrm{K}$, Osborn $\mathrm{M}$. The reliability of molecular weight determinations by dodecylsulfate-polyacrylamide gel electrophoresis. J Biol Chem 1969;244: 4406-12.

${ }^{19}$ Rodeghiero F, Barbui T, Dal Belin A. Simplified method for the polyacrilamide gel electrophoresis of fibrin. G Arterioscler 1977; new series 2:23-9.

${ }^{20}$ Finlayson JS, Morton RO. Gel electrophoresis for assessing fibrin crosslinking: a precaution. Clin Chem Acta 1972;36:254-6.

${ }^{21}$ Chung SI. Comparative studies on tissue transglutaminase and factor XIII. Ann N Y Acad Sci 1972;202:240-55.

${ }^{22}$ Miloszewski K, Losowsky MS. The half-life of factor XIII in vivo. Brit J Haemat 1970;19:685-90.

Requests for reprints to: Professor T Barbui, Divisione di Ematologia, Ospedale Civile, Vicenza, Italy. 